\title{
Long term effects of smoke inhalation in survivors of the King's Cross underground station fire
}

\author{
P W Fogarty, P J M George, M Solomon, S G Spiro, R F Armstrong
}

\begin{abstract}
Background In most accidents causing smoke inhalation only a few victims actually inhale the smoke. The fire at King's Cross provided an opportunity to assess the long term effects of smoke inhalation in a larger number of patients.

Methods Fourteen survivors from the King's Cross underground station fire were assessed for respiratory disability six months after the disaster and 10 were reassessed at two years. All had inhaled substantial quantities of smoke and 10 had skin burns of differing severity.

Results Six months after the fire nine survivors admitted to one or more symptoms, which included hoarseness (two cases), cough (five cases), and breathlessness (six cases); and a survivor with asthma noted a worsening of his symptoms. The remaining five denied new symptoms. Peak expiratory flow, spirometric indices, and transfer factor for carbon monoxide were within the predicted normal ranges. The mean residual volume, however, was greater than the predicted value and the mean maximum expiratory flow at $25 \%$ of vital capacity $\left(\dot{V}_{25}\right)$ less than predicted, with no significant difference between smokers $(\mathbf{n}=7)$ and non-smokers $(\mathbf{n}=7)$. At least one of these ventilatory defects, suggesting small airways obstruction, was present in 11 survivors at six months and they had persisted in the seven patients who were reassessed at two years.
\end{abstract}

Conclusion Smoke inhalation may be associated with injury to the small airways.

Smoke inhalation is a major immediate cause of morbidity and mortality in victims of fire tragedies. ${ }^{12}$ Although the acute effects are well documented, ${ }^{3}$ relatively little is known of the long term effects on the respiratory tract Much of the information available is confined to firemen, in whom smoke inhalation is an occupational hazard ${ }^{4-7}$ and, although the evidence is conflicting, long term respiratory disability is generally assumed to be rare.

We describe findings from a long term follow up study of survivors from the underground station fire at King's Cross, London, which occurred on 18 November 1987. Some survivors from the fire were taken to hospital with skin burns and the effects of smoke inhalation. Fourteen were assessed for respiratory disability six months after the disaster and 10 were reassessed at two years.

\section{Survivors}

After the King's Cross fire a fund was set up for the victims and their families. Victims were identified from police and hospital lists and from letters received from people affected in any way by the fire. There were 31 fatalities at the scene of the fire and a further 27 people are known to have been injured. Fifteen of this latter group suffered from smoke inhalation; three required assisted ventilation and one died in hospital. The remaining 14 survivors with a history of smoke inhalation were referred for assessment.

In the study group of 14 survivors (11 men) seven were non-smokers and seven smokers. The mean age was 36 with a range of 21-55 years. One patient had mild asthma before the fire and two had a history of angina, one of whom had a history suggesting obstructive sleep apnoea related to obesity. The remaining 11 had no important medical history.

\section{Methods of assessment}

All 14 survivors were assessed six to seven months after the fire and 10 were reassessed at 20-25 months. At the initial assessment each was asked to give details of their involvement in the fire and of the events immediately afterwards. They were asked specifically about their respiratory and laryngeal symptoms before and after the fire; breathlessness was graded on the basis of the Medical Research Council (MRC) questionnaire. $^{8}$ Two survivors who had smoked heavily before the fire admitted to some exertional breathlessness (MRC grade 2), and one non-smoker had asthma. All were examined by one of two doctors (PJMG or RFA), particular attention being paid to abnormalities of the respiratory system and to the extent and site of burns.

Dynamic lung volumes were assessed by flow-volume loop analysis (Gould Pulmograph), values from the best of three consistent loops being used. Static lung volumes were measured by whole body plethysmography. Transfer factor for carbon monoxide (TLCO) was measured by the single breath technique (PK Morgan Ltd) with the simultaneous measurement of alveolar volume by helium to calculate the transfer coefficient (KCo). The observed values were compared with predicted values from Cotes $^{9}$ and expressed as standard- 
Table 1 Details of smoke inhalation, burns, and symptoms six months and two years after the fire for smokers and non-smokers

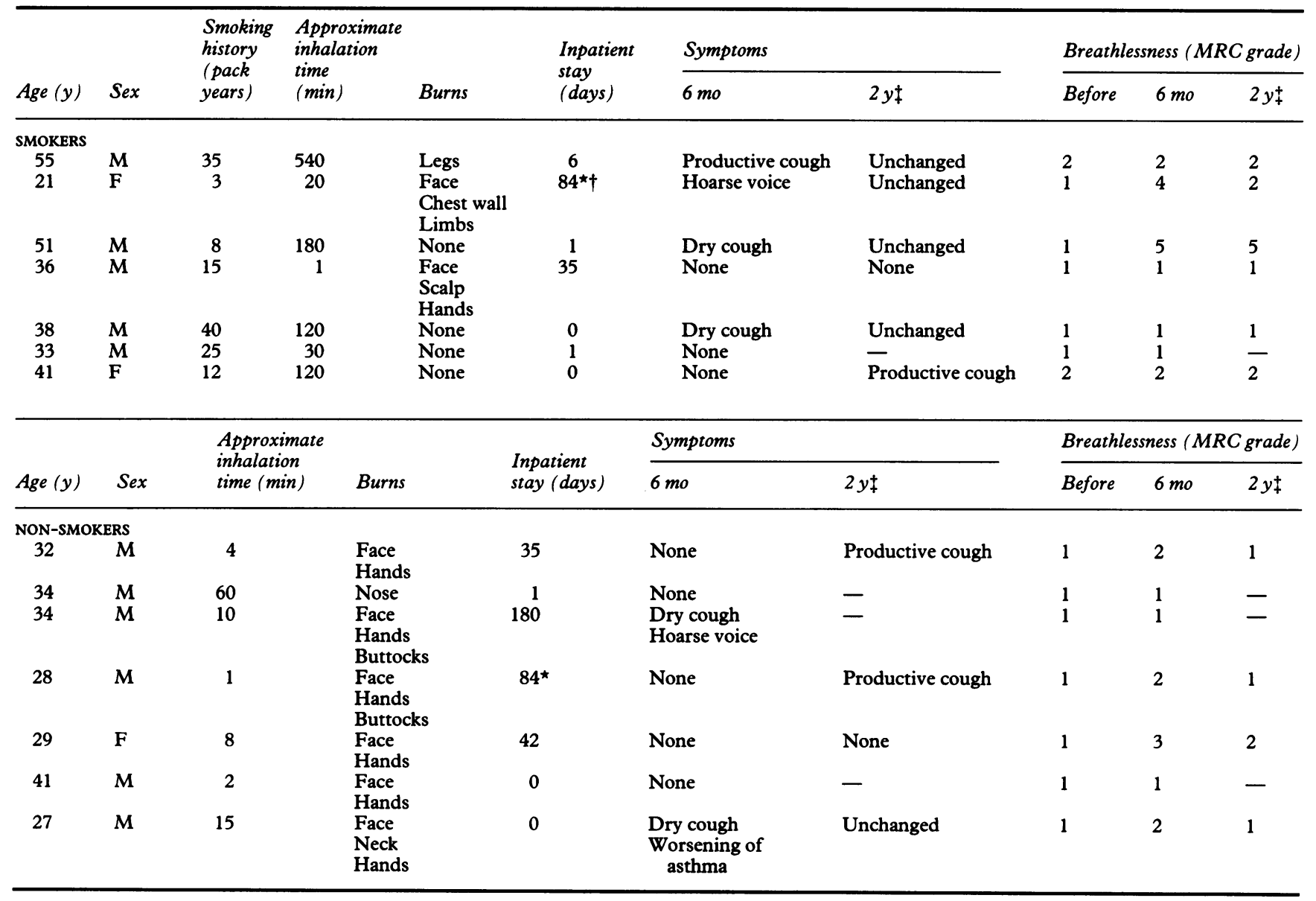

$\star^{\star}$ Patient was intubated. $\nmid$ Patient developed the adult respiratory distress syndrome. $¥$ Dashes indicate missing data.

ised residuals $(\mathrm{SRs})^{10}$ on the two occasions to allow for the range of values found in a reference population $(1.96 \mathrm{SRs}=95 \%$ confidence intervals). SRs were obtained as follows:

Standardised residual $=$ observed value - predicted value . residual standard deviation

Values for the residual standard deviation were taken from summary equations derived by a working party of the European Coal and Steel Community. ${ }^{11}$

\section{STATISTICAL ANALYSIS}

Change with time in indices of lung function within patients was assessed by the paired Student's $t$ test, and comparisons between groups by the unpaired Student's $t$ test.

\section{Results}

Details of smoke inhalation, skin burns, and symptoms after the fire are given in table 1 for the 14 survivors assessed at six months and the 10 reassessed at two years.

EXPOSURE TO THE FIRE

Five survivors had been rescuers during the fire; two were firemen, one a policeman, and two British Rail employees. The remainder were passengers using the underground. The estimated duration of smoke inhalation ranged from one minute to nine hours (mean 80 minutes). The rescuers tended to have longer periods of exposure to smoke, though the duration could not be recalled with confidence. The duration of smoke exposure was not thought to bear a close relation to severity as some survivors with relatively long exposures had been able to take refuge in side rooms in the underground station and so avoid the most dense smoke. Nine survivors had skin burns; in seven these were limited to their faces and hands, but two had more extensive burns that included the face.

\section{HOSPITAL ATTENDANCE}

Thirteen of the survivors attended a hospital after the fire. Two were discharged from the accident and emergency department and 11 admitted for periods ranging from 24 hours (three cases) to more than six months (one case). The main reason for hospital admission was for the management of burns. Two required endotracheal intubation for laryngeal oedema caused by thermal injury; one was extubated after 24 hours, and the other required ventilation for 24 days as a result of the adult respiratory distress syndrome.

\section{SYMPTOMS}

Most survivors had cough, hoarseness, and varying degrees of breathlessness immediately after the fire. Although there was a gradual improvement, nine survivors were troubled by 
Table 2 Mean (SD) indices of respiratory function in survivors of the King's Cross underground station fire

\begin{tabular}{|c|c|c|c|c|c|c|c|c|}
\hline \multirow[b]{3}{*}{ FVC (1) } & \multicolumn{4}{|c|}{ Six months after fire } & \multicolumn{4}{|c|}{ Two years after fire $\dagger$} \\
\hline & \multicolumn{2}{|c|}{ Smokers $(n=7)$} & \multicolumn{2}{|c|}{ Non-smokers $(n=7)$} & \multicolumn{2}{|c|}{ Smokers $(n=6)$} & \multicolumn{2}{|c|}{ Non-smokers $(n=4)$} \\
\hline & $4 \cdot 23$ & $(1 \cdot 27)$ & 5.06 & $(0 \cdot 66)$ & $\begin{array}{r}3.89 \\
{[3.92}\end{array}$ & $\begin{array}{l}(0.74) \\
(1.06)]\end{array}$ & $\begin{array}{r}4 \cdot 54 \\
{[4 \cdot 77}\end{array}$ & $\begin{array}{l}(0.63) \\
(0.70)]\end{array}$ \\
\hline TLC (1) & 6.61 & $(1 \cdot 78)$ & $7 \cdot 30$ & $(0.99)$ & $\begin{array}{r}6.41 \\
{[6 \cdot 21}\end{array}$ & $\begin{array}{l}(1.42) \\
(1.57)]\end{array}$ & $\begin{array}{r}6 \cdot 72 \\
6 \cdot 68\end{array}$ & $\begin{array}{l}(1.03) \\
(0.67)]\end{array}$ \\
\hline FRC (1) & $3 \cdot 21$ & $(1 \cdot 18)$ & 3.68 & $(0.55)$ & $\begin{array}{r}3.33 \\
2.99\end{array}$ & $\begin{array}{l}(1 \cdot 20) \\
(1 \cdot 12)]\end{array}$ & $\begin{array}{r}3.36 \\
3.45\end{array}$ & $\begin{array}{l}(0.49) \\
(0.52)]\end{array}$ \\
\hline RV (1) & $2 \cdot 51$ & $(1.05)$ & $2 \cdot 32$ & $(0 \cdot 61)$ & $\begin{array}{r}2.51 \\
{[2.31}\end{array}$ & $\begin{array}{l}(1.08) \\
(0.99)]\end{array}$ & $\begin{array}{r}2.49 \\
{[1.99}\end{array}$ & $\begin{array}{l}(0.86) \\
(0.56)]\end{array}$ \\
\hline RV/TLC (\%) & $35 \cdot 61$ & $(9 \cdot 31)$ & $31 \cdot 80$ & $(7 \cdot 29)$ & $\begin{array}{r}38 \cdot 17 \\
{[34 \cdot 62}\end{array}$ & $\begin{array}{l}(12.32) \\
(9 \cdot 78)]\end{array}$ & $\begin{array}{r}32 \cdot 75 \\
{[30 \cdot 24}\end{array}$ & $\begin{array}{l}(7 \cdot 23) \\
(9 \cdot 72)]\end{array}$ \\
\hline $\mathrm{FEV}_{1}(\mathbf{l} / \mathbf{s})$ & $3 \cdot 24$ & $(0 \cdot 72)$ & 3.93 & $(0 \cdot 36)$ & $\begin{array}{r}3.08 \\
{[3.39}\end{array}$ & $\begin{array}{l}(0.25) \\
(0.33)]\end{array}$ & $\begin{array}{r}3.69 \\
{[3.80}\end{array}$ & $\begin{array}{l}(0.36) \\
(0.44)]\end{array}$ \\
\hline $\mathrm{FEV}_{1} / \mathrm{FVC}(\%)$ & 78.27 & $(8 \cdot 56)$ & $78 \cdot 16$ & $(6 \cdot 80)$ & $\begin{array}{r}74.34 \\
{[80.06}\end{array}$ & $\begin{array}{l}(8.62) \\
(6.92)]^{\star \star}\end{array}$ & $\begin{array}{r}81 \cdot 50 \\
{[80 \cdot 28}\end{array}$ & $\begin{array}{l}(5 \cdot 32) \\
(6 \cdot 75)]\end{array}$ \\
\hline $\operatorname{PEF}(1 / \min )$ & 571 & (134) & 630 & (82) & $\begin{array}{r}465 \\
{[619}\end{array}$ & $\begin{array}{l}(73) \\
(86)]^{\star \star}\end{array}$ & $\begin{array}{r}526 \\
{[627}\end{array}$ & $\begin{array}{l}(97) \\
(96)]\end{array}$ \\
\hline$\dot{\mathrm{V}}_{50}(\mathrm{l} / \mathrm{s})$ & 3.89 & $(1.06)$ & 4.05 & $(0.96)$ & $\begin{array}{r}3 \cdot 23 \\
{[4 \cdot 17}\end{array}$ & $\begin{array}{l}(1 \cdot 11) \\
(1.03)]\end{array}$ & $\begin{array}{r}3 \cdot 80 \\
{[4 \cdot 24}\end{array}$ & $\begin{array}{l}(1 \cdot 55) \\
(1 \cdot 12)]\end{array}$ \\
\hline$\dot{\mathrm{V}}_{25}(\mathrm{l} / \mathrm{s})$ & $1 \cdot 11$ & $(0 \cdot 38)$ & 1.50 & $(0.43)$ & $\begin{array}{r}0.97 \\
{[1 \cdot 18}\end{array}$ & $\begin{array}{l}(0.61) \\
(0.41)]\end{array}$ & $\begin{array}{l}1.51 \\
{[1.45}\end{array}$ & $\begin{array}{l}(0.62) \\
(0.52)]\end{array}$ \\
\hline TLCO $(\mathrm{mmol} / \mathrm{kPa} / \mathrm{s})$ & $9 \cdot 41$ & $(2 \cdot 47)$ & $11 \cdot 36$ & $(2 \cdot 58)$ & $\begin{array}{r}9 \cdot 73 \\
{[8 \cdot 64}\end{array}$ & $\begin{array}{l}(1 \cdot 70) \\
(1 \cdot 53)]^{\star}\end{array}$ & $\begin{array}{r}11.56 \\
{[10.52}\end{array}$ & $\begin{array}{l}(3.46) \\
(3.32)]\end{array}$ \\
\hline $\mathrm{Kco}(\mathrm{mmol} / \mathrm{kPa} / \mathrm{l} / \mathrm{s})$ & $1 \cdot 72$ & $(0 \cdot 32)$ & 1.89 & $(0 \cdot 34)$ & $\begin{array}{r}1.87 \\
{[1.66}\end{array}$ & $\begin{array}{l}(0 \cdot 30) \\
(0 \cdot 30)]^{\star}\end{array}$ & $\begin{array}{r}2.02 \\
{[1.86}\end{array}$ & $\begin{array}{l}(0.45) \\
(0.43)]\end{array}$ \\
\hline
\end{tabular}

${ }^{\star} \mathrm{p}<0.005 ;{ }^{\star \star} \mathrm{p}<0.001$ (paired Student's $t$ test).

† Mean values obtained at six months in 10 of the 14 survivors who attended both assessments are given in square brackets to illustrate change with time.

FVC-forced vital capacity; TLC — total lung capacity; FRC-functional residual capacity; RV_residual volume; FEV - forced expiratory volume in one second; PEF-peak expiratory flow; $\dot{\mathrm{V}}_{50}, \dot{\mathrm{V}}_{25}$-flow at $50 \%$ and $25 \%$ of vital capacity; TLCo-carbon monoxide transfer factor; Kco-transfer coefficient.

one or more of these symptoms when assessed at six months (table 1).

Of the 10 survivors reassessed at two years, eight had symptoms. Although breathlessness had improved in most cases, cough had become more troublesome. Four volunteered that they had become particularly prone to chest infections and had required repeated courses of antibiotics. One noticed that his sputum was streaked with blood with each infection; although bronchiectasis was suspected, it was not confirmed by high resolution computed tomography.

The patient with asthma complained of worsening asthmatic symptoms after the fire; at both the six month and the two year assessment he said that his bronchodilator consumption had increased from one inhaler of salbutamol a month to one a week.

\section{RESPIRATORY FUNCTION TESTS}

Mean values for each index of lung function are given in table 2 . As the data at six months and two years are not strictly comparable, as four of the survivors did not attend at two years, changes with time were evaluated on the data from survivors who attended both assessments. No significant changes were observed in the non-smoking group. There was a significant decline in mean PEF and mean forced expiratory volume $\left(\mathrm{FEV}_{1}\right)$ /forced vital capacity (FVC) ratio and a significant increase in mean TLCo and Kco in the smoking group between the two visits. These indices remained within their predicted normal ranges, however.

Mean values for peak expiratory flow, spirometric indices, TLCO, and KCo lay within the $95 \%$ confidence intervals of predicted values in both smokers and non-smokers at six months and two years (figure). Although mean values for $\mathrm{FEV}_{1}$ and $\mathrm{FVC}$ were lower in smokers than non-smokers, the differences were not significant.

The most abnormal lung function indices were residual volume (RV) and maximum expiratory flow at $25 \%$ of vital capacity $\left(\dot{V}_{25}\right)$. Mean RV lay above the upper $95 \%$ confidence limit and mean $\dot{V}_{25}$ lay below the lower $95 \%$ confidence limit of the predicted values in both smokers and non-smokers. At least one of these ventilatory defects was present in 11 survivors at six months and in the seven reassessed at two years.

The two survivors who developed laryngeal oedema requiring endotracheal intubation had no evidence of inspiratory flow limitation. The patient who developed the adult respiratory distress syndrome had values for all indices of lung function that were within the normal range at six months and two years. No relationship appeared to exist between the estimated duration of smoke inhalation and the subsequent symptoms or abnormalities of respiratory function of the survivors, though their recollection of both the duration and the severity of smoke inhalation was extremely poor.

\section{Discussion}

Studies on the effects of smoke inhalation have produced inconsistent results. Although acute reductions in $\mathrm{FEV}_{1}$ have been documented immediately after firefighting, ${ }^{1213}$ evidence of impaired lung function was not found in firemen assessed one month after an episode of severe smoke inhalation. ${ }^{4}$ Severe and persistent respiratory disability has been observed in a fireman, however, who inhaled smoke when his air supply ran out, and evidence of small 


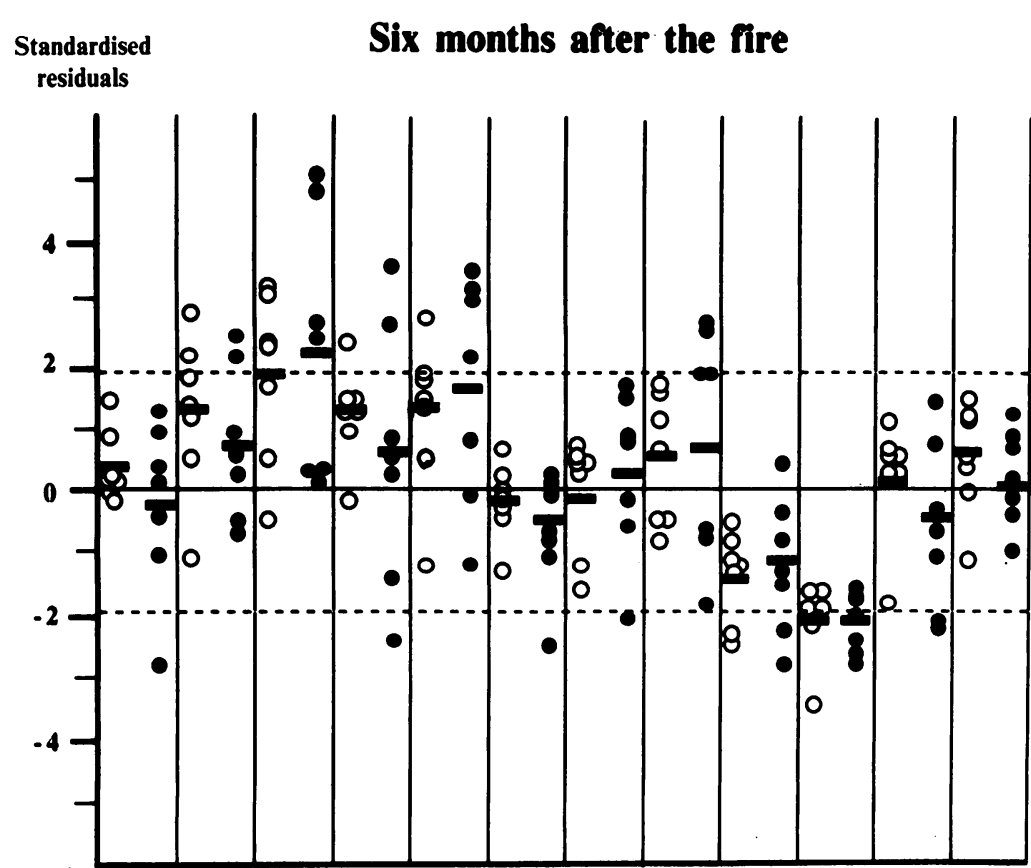

Two years after the fire

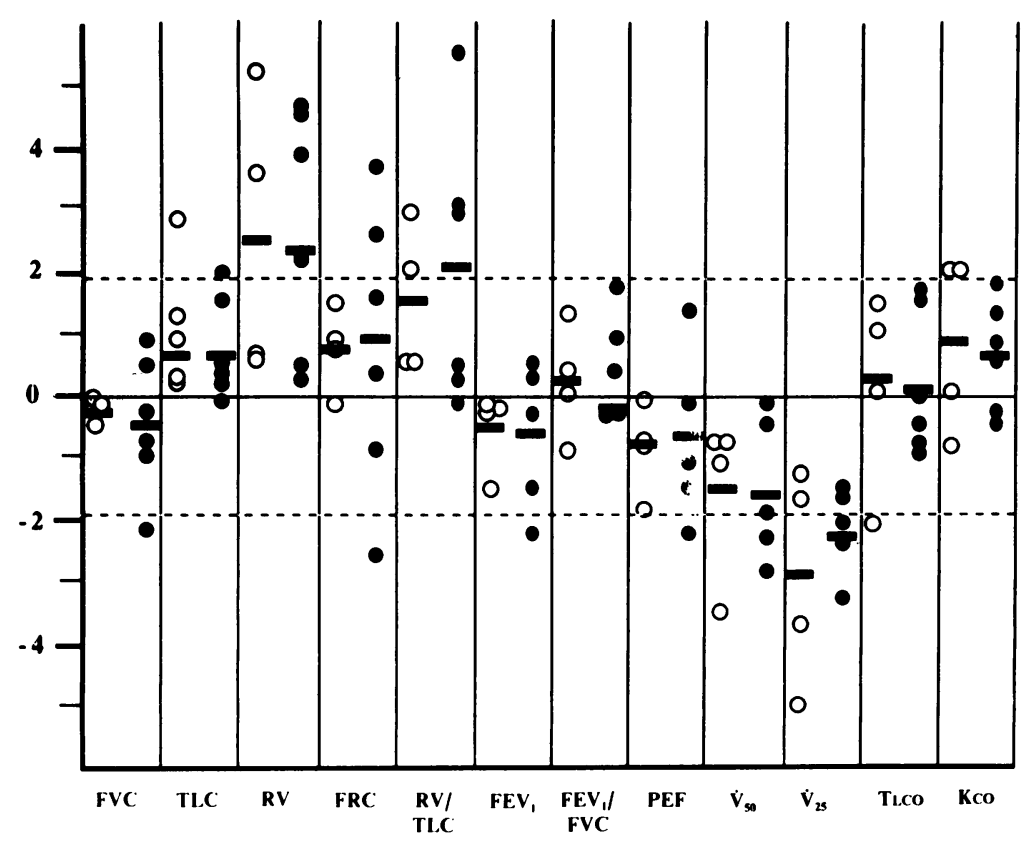

Indices of lung function expressed as standardised residuals for non-smokers ( $O)$ and smokers ( ) six months and two years after the King's Cross fire. Horizontal solid lines represent mean values for each group; dotted lines represent upper and lower $95 \%$ confidence limits. Abbreviations as in table 2. on the long term effects of accidental smoke inhalation, the findings are also inconsistent. No evidence of long term functional impairment was found in 27 patients convalescing from burns, ${ }^{14}$ whereas other studies have reported airflow obstruction immediately after smoke inhalation, ${ }^{15} 16$ with gradual resolution over months. ${ }^{16}$ There are case reports of persistent structural and functional abnormalities of the respiratory tract after thermal injuries and smoke inhalation, including stenoses of the trachea ${ }^{17}$ and bronchial tree, ${ }^{18}$ bronchiectasis, ${ }^{17-19}$ obliterative bronchiolitis, ${ }^{18-20}$ and small airways disease unresponsive to corticosteroid treatment. ${ }^{21}$

The King's Cross fire provided a rare opportunity to study the effects of inhalation of smoke from a common source in a relatively large number of victims. The enclosed space of the underground station probably increased the amount of smoke inhaled, which accounted for all fatalities in the booking hall of the station. Anti-graffiti paint and varnish on the escalators, balustrades, and advertising panels of the station contained a polyurethane base that would have generated cyanide gas and other toxic products of combustion. ${ }^{22}$ Precise information on the particulate and gaseous components of the smoke could not be obtained and the duration and severity of smoke exposure could not be quantified accurately.

As in other studies of accidental smoke inhalation, control data with which to compare these survivors' lung function measurements are not reaily available. Our results have been compared with predicted normal values and expressed in terms of standardised residuals to allow for the changes that would occur over the time course of the study. ${ }^{10}$

The pattern of ventilatory abnormality that emerged in both the smoking and the nonsmoking groups was for mean $\mathrm{RV}$ and $\dot{\mathrm{V}}_{25}$ to be just outside the upper and lower $95 \%$ confidence limits respectively. As flow-volume loop analysis and measurements of carbon monoxide gas transfer showed no evidence of large airways disease or changes of emphysema, the ventilatory defect would appear to have been confined to the small airways. In the absence of baseline lung function data, we cannot assess the effects of previous cigarette smoking and asthma, though the similar findings in smokers and non-smokers and the finding of similar changes in victims from other fires ${ }^{20}$ suggest that smoke inhalation made an important contribution.

Symptoms in some of the survivors from the King's Cross fire had improved by the time of the first assessment at six months. Victims of accidental ${ }^{1516}$ and occupational smoke exposure $^{1213}$ may develop acute airflow obstruction and bronchial reactivity may be increased immediately after an episode of smoke inhalation, ${ }^{1323}$ with decline by three months. ${ }^{23} \mathrm{~A}$ temporary increase in airway reactivity may explain the transient symptoms described by some of the survivors.

The finding of sustained small airways dysfunction in most of the survivors suggests that smoke inhalation may lead to more damage to 
the respiratory tract than has previously been recognised. The number of survivors with abnormal lung function is small, however, and more information on the long term effects of smoke inhalation in victims from other fire tragedies is now needed.

We are grateful to Mrs Fiona Chapman for her technical We are grateful to Mrs Fiona Chapman for her technical trative work. We would also like to thank the survivors for giving up their time to be investigated.

1 Zikria BA, Weston GC, Chodoff M, Ferrer JM. Smoke and carbon monoxide poisoning in fire victims. J Trauma 1972;12:641-5.

2 Thompson PB, Herndon DN, Traber DL, Abston S. Effects on mortality of inhalation injury. $J$ Trauma 1986;26:163-5.

3 Clark RJ, Beeley JM. Smoke inhalation. Br J Hospital Med 1989;41:252-9.

4 Tashkin DP, Genovesi MG, Chopra S, Coulson A, Simmons M. Respiratory status of Los Angeles firemen: one month follow-up after inhalation of dense smoke. Chest 1977;71:445-9.

5 Loke J, Farmer W, Matthay RA, Putman CE, WalkerSmith GJ. Acute and chronic effects of fire fighting on pulmonary function. Chest 1980;77:369-73.

6 Peters JM, Theriault GP, Fine LJ, Wegman DH. Chronic effect of firefighting on pulmonary function N Engl J Med 1974;291:1320-2

7 Musk AW, Peters JM, Bernstein L, Rubin C, Monroe CB. Pulmonary function in firefighters: a six year follow-up in the Boston Fire Department. Am J Ind Med 1982;3:3-9.

8 Medical Research Council. Questionnaire on respiratory symptoms. 1st ed. London: Medical Research Council, 1966.

9 Cotes JE. Lung function: principles and application in medicine. 4th ed. Oxford: Blackwell, 1979.
10 Miller MR, Pincock AC. Predicted values: how should we use them? Thorax 1988;43:265-7.

11 Quanjer PH, ed. Standardised lung function testing. European Coal and Steel Community recommendations. Bull Eur Physiopathol Respir 1983;19(suppl 5): 1-93.

12 Musk AW, Smith TJ, Peters JM, McClaughlin E. Pulmonary function in firefighters: acute changes in ventilatory capacity and their correlates. $\mathrm{Br} J$ Ind Med 1979;36:29-34.

13 Sherman CB, Barnhart S, Miller MF, Segal MR, Aitken $M$, Schoene $R$, et al. Firefighting acutely increases airway responsiveness. Am Rev Respir Dis 1989;140: 185-90.

14 Morris AH, Spitzer KW. Lung function in convalescent burn patients. Am Rev Respir Dis 1973;108:989-93.

15 Landa J, Avery WG, Sackner MA. Some physiologic observations in smoke inhalation. Chest 1972;61:62-4.

16 Whitener DR, Whitener LM, Robertson KJ, Baxter $\mathrm{CR}$, Pierce AK. Pulmonary function measurements in patients with thermal injury and smoke inhalation. $\mathrm{Am}$ Rev Respir Dis 1980;122:731-9.

17 Perez-Guerra F, Walsh RE, Sagel SS. Bronchiolitis obliterans and tracheal stenosis-late complications of inhalation burn. JAMA 1971;21:1568-70

18 Donnellan WI, Poticha SM, Hollinger PH. Management and complications of severe pulmonary burn. JAMA 1965;194:1323-5.

19 Slutzker AD, Kinn R, Said SI. Bronchiectasis and progressive respiratory failure following smoke inhalation. Chest 1989;95:1349-50.

20 Kirkpatrick MB, Bass JB. Severe obstructive lung disease after smoke inhalation. Chest 1979;76:108-10.

21 Cooke NT, Cobley AJ, Armstrong RF. Airflow obstruction after smoke inhalation. Anaesthesia 1982;37: $830-2$.

22 Summer W, Haponik E. Inhalation of irritant gases. Clin Chest Med 1981;2:273-87.

23 Kinsella J, Carter R, Reid WH, Campbell D, Clark CJ. Increased airway reactivity to histamine following smoke inhalation injury [abstract]. Thorax 1989;44: $362 P$. 